\title{
Establishment of an Efficient In Vitro Culture System in Dicentra $\times$ hybrida ${ }^{+}$
}

\section{Dariusz Kulus}

Laboratory of Ornamental Plants and Vegetable Crops, Department of Environmental Bases of Agriculture and Horticulture, Faculty of Agriculture and Biotechnology, UTP University of Science and Technology in Bydgoszcz, Bernardyńska 6, PL-85-029 Bydgoszcz, Poland; dkulus@gmail.com; Tel.: +48-52-374-95-36

† Presented at the 1st International Electronic Conference on Plant Science, 1-15 December 2020; Available online: https://iecps2020.sciforum.net/.

\begin{abstract}
Dicentra $\times$ hybrida is a popular ornamental hybrid, cultivated in parks and gardens worldwide. To date, there are no reports on establishing a plant tissue culture system in this species. This study aimed to develop an efficient micropropagation protocol in D. $\times$ hybrida 'Amore Rose' for further reproduction and breeding. Shoots of in vivo-grown plants were dissected and washed with running tap water. Next, shoot segments were bathed in tap water with a drop of detergent for $30 \mathrm{~min}$ and, then, immersed in 70\% (v/v) ethanol for $1 \mathrm{~min}$. Following the initial disinfection, explants were surface sterilized with $0.4-0.8 \%(v / v)$ sodium hypochlorite $(\mathrm{NaOCl})$ for 20 min and, finally, washed thrice with sterile distilled water (20 min each). The rosette explants were inoculated polarly in the modified Murashige and Skoog medium devoid of plant growth regulators and cultured in a growth room with a 16-h photoperiod. After one month, contamination-free explants were transferred on the kinetin-supplemented medium. The disinfection efficiency reached $10-40 \%$. All disinfected explants were capable to develop healthy shoots. The multiplication ratio, i.e., the number of secondary explants produced reached up to 6.0. All developed shoots regenerated roots spontaneously. The obtained plantlets were successfully acclimatized to ex vitro conditions. The described here protocol can be recommended for in vitro propagation of Dicentra $\times$ hybrida.
\end{abstract}

Keywords: axillary bud; bleeding heart; disinfection; micropropagation; ornamental plants; sodium hypochlorite; tissue culture

\section{Introduction}

Micropropagation, i.e., the production of plants under strictly controlled and aseptic laboratory conditions, is a modern method for the rapid obtaining of high-quality plant material. Various micropropagation techniques are known; i.e., axillary bud activation, adventitious organogenesis, and somatic embryogenesis. They are based on totipotency-an exceptional phenomenon first suggested in 1902 by Gottlieb Haberlandt (1854-1945), an Austrian botanist, the "Father of Tissue Culture" [1]. In the 1950s, Steward and co-workers pioneered in regenerating complete carrot microshoots from isolated phloem cells, confirming the great regeneration potential of plants. In the following decades, tremendous progress in tissue culture systems has been made [1]. Currently, this technology is commonly used for numerous purposes, including large-scale reproduction, in breeding programs (haploid production, protoplast fusion, mutagenesis, transgenesis, and somaclonal-variation-studies), as well as storage of plant material in in vitro tissue banks or at cryogenics [2]. However, there is no universal method that is effective for the reproduction of all plant species; a protocol that works fine for one species, or even a single cultivar, is often not successful with another. Consequently, broad-spectra experiments are needed when introducing new plant species to in vitro conditions. 
Dicentra, known as bleeding-hearts, is a genus of eight species of herbaceous plants, native to eastern Asia and North America. It is a member of the Fumariaceae botanical family, sometimes referred to as a subfamily of the Papaveraceae (the poppy family). Dicentra 'Amore Rose' (fern-leaf bleeding heart) is a compact perennial prized for its ornamental lacy blue-green foliage and abundant rose flowers, blooming over a long season extending from late spring until late summer [3]. Despite its commercial success, there are no reports available on micropropagation of this species. Therefore, the aim of this study was to develop an efficient micropropagation protocol in D. $\times$ hybrida 'Amore Rose' for further reproduction, storage, and breeding.

\section{Experiments}

Plants of Dicentra $\times$ hybrida 'Amore Rose' grown in the glasshouse of the Laboratory of Ornamental Plants and Vegetable Crops, UTP University of Science and Technology in Bydgoszcz,

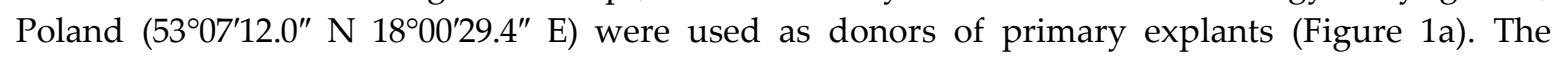
experiments were performed from July to October 2019.

Shoots of in vivo-grown plants were dissected and washed thoroughly with running tap water. Next, shoot segments were bathed in tap water with a drop of detergent for $30 \mathrm{~min}$ and, then, immersed in $70 \%(v / v)$ ethanol for 1 min. Following the initial disinfection, explants were surface sterilized with $0.4 \%, 0.6 \%$, or $0.8 \%(v / v)$ sodium hypochlorite $(\mathrm{NaOCl})$ for $20 \mathrm{~min}$ (with agitation 120 $\mathrm{rpm}$ ) under aseptic conditions and, finally, washed thrice with sterile distilled water (20 min each; $120 \mathrm{rpm}$ agitation). The rosette explants were inoculated polarly in the modified MS medium [4] devoid of plant growth regulators with an increased by half content of calcium and iron, supplemented with $3 \%(w / v)$ sucrose and $0.8 \%(w / v)$ agar (Biocrop, Poland). The $\mathrm{pH}$ of the medium was set at 5.8 (with $0.1 \mathrm{M} \mathrm{NaOH}$ and $0.1 \mathrm{M} \mathrm{HCl}$ ) after adding all components and before sterilization at $121{ }^{\circ} \mathrm{C}(20 \mathrm{~min})$ and $105 \mathrm{kPa}$. One explant was cultured in a single culture vessel-100-mL Erlenmeyer flask with $20 \mathrm{~mL}$ of medium, sealed with aluminum foil (Figure $2 \mathrm{~b}$ ). After one month, the developed contamination-free shoots were transferred to $350-\mathrm{mL}$ glass jars with $40 \mathrm{~mL}$ of the same modified MS medium supplemented with $1.0 \mathrm{mg} \cdot \mathrm{L}^{-1}$ kinetin (KIN) for another 30 days.

Tissue cultures were kept in a growth room at $24^{\circ} \mathrm{C} \pm 1{ }^{\circ} \mathrm{C}$ with 16 -h photoperiod and photosynthetic photon flux density of approximately $25 \mu \mathrm{mol} \cdot \mathrm{m}^{-2} \cdot \mathrm{s}^{-1}$ provided by standard cool daylight TLD 54/36W fluorescent tubes (Koninklijke Philips Electronics N.V., Amsterdam, The Netherlands).

After two months of in vitro culture, the complete plantlets were taken out of the jar, the residues of agar medium were carefully removed not to damage the root system, and bleeding hearts were planted in pots filled with peat substrate and perlite (1:1). The plants were covered with perforated foil and spayed for one week. Acclimatization was performed on benches in a glasshouse in natural light conditions for two weeks.

The effectiveness of disinfection protocols was evaluated one month after tissue culture initiation; the share of axenic cultures, bacterial and fungal contaminations were counted. Two months after tissue culture initiation, the efficiency of micropropagation was evaluated -the length of shoots, number of leaves and secondary explants produced (multiplication ratio) were assessed. The efficiency of rhizogenesis and acclimatization (survival to ex vitro conditions) were also included.

The experiment was performed in a completely randomized design. Each (ex)plant was treated as a single repetition. The analysis of variance (ANOVA) was performed and means were compared with Fisher's exact post-hoc test at the significance level $p \leq 0.05$.

\section{Results}

Only $10 \%$ of clean/axenic cultures were obtained when using $0.4 \% \mathrm{NaOCl}$. After elevating the concentration of the sterilizing agent to $0.6 \%$ and $0.8 \%$, the disinfection efficiency increased to $20 \%$ and $40 \%$, respectively (Table 1). Fungal colonies were white and fluffy, while bacterial ones-creamy and opaque. More fungal contaminations were found when lower concentrations $(0.4 \%$ and $0.6 \%)$ of $\mathrm{NaOCl}$ were used $(60-90 \%)$. Conversely, more bacterial colonies were reported with the highest $(0.8 \%)$ concentration of $\mathrm{NaOCl}$ (in $40 \%$ of cultures) compared to fungal ones (20\%; Table 1$)$. Aseptic 
explants developed healthy leaves in the MS0 medium during the 30 days of initial culture. Even more vigorous leaves and axillary buds were produced on the proliferation MS medium with KIN (Figure 1c). The shoot length and number of leaves per shoot decreased from 70 to $40 \mathrm{~mm}$ and from 44 to 10, respectively, with the increase in $\mathrm{NaOCl}$ concentration (Table 1). A similar tendency was observed with the multiplication ratio (number of secondary explants/rosettes produced), which reached $5.0-6.0$ after $0.4 \%$ and $0.6 \% \mathrm{NaOCl}$ treatments, and 2.0 with $0.8 \% \mathrm{NaOCl}$ (Table 1). All shoots were able to regenerate green adventitious roots (Table 1; Figure 1d). Acclimatization was fully successful with a $100 \%$ survival rate. All plantlets transferred to the glasshouse maintained vigorous and high quality (Figure 1e). The plants were morphologically similar to each other and started to develop new leaves in the second week of ex vitro growth.
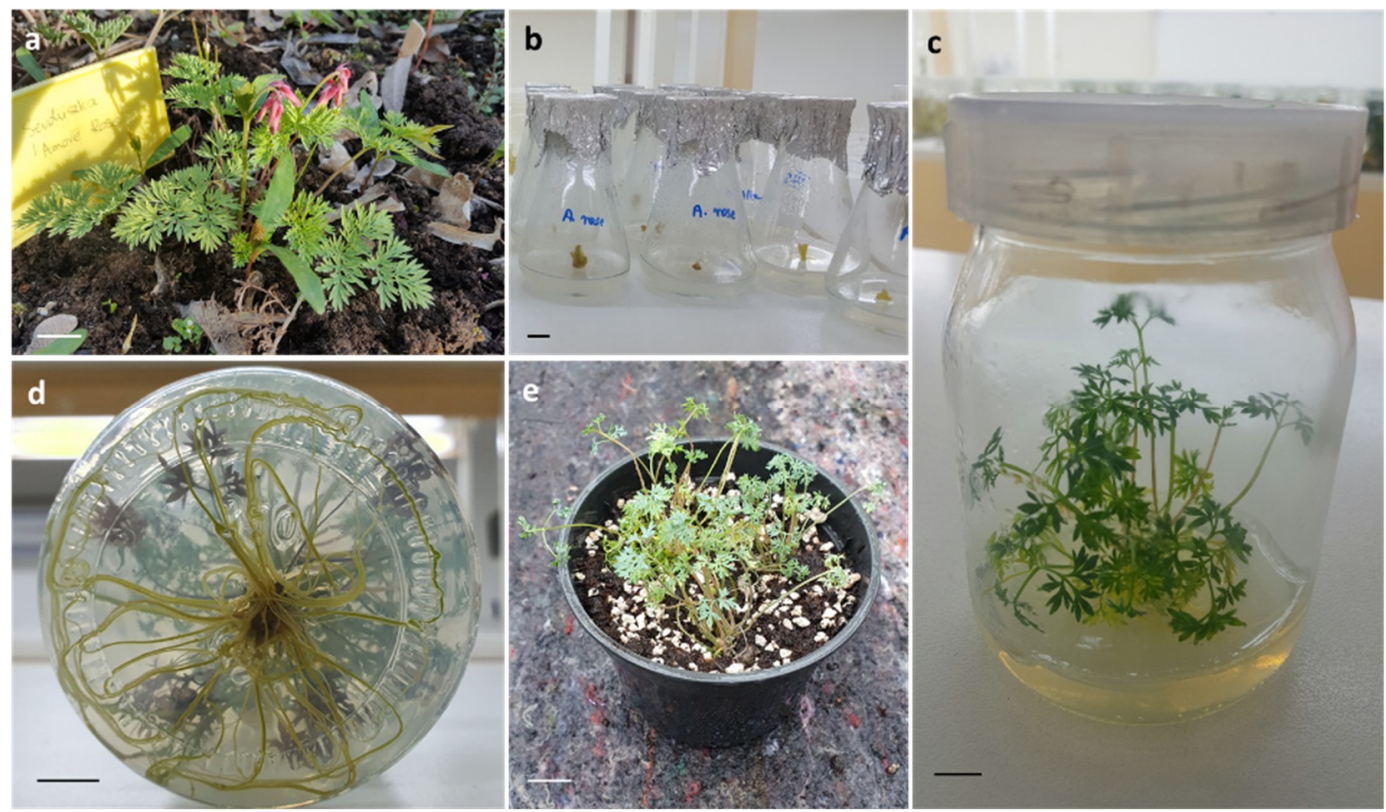

Figure 1. Micropropagation of Dicentra $\times$ hybrida 'Amore Rose': (a) flowering plants in the glasshouse; (b) primary explants in the PGRs-free MS medium; (c) fully developed microshoots of bleeding heart; (d) adventitious roots after two months of in vitro culture; (e) plantlets acclimatized to ex vitro conditions. Bar $=1 \mathrm{~cm}$.

Table 1. Efficiency of a micropropagation protocol in Dicentra $\times$ hybrida 'Amore Rose'.

\begin{tabular}{|c|c|c|c|c|c|c|c|c|}
\hline \multirow[b]{2}{*}{$\begin{array}{c}\mathrm{NaOCl} \\
{[\%]}\end{array}$} & \multirow{2}{*}{$\begin{array}{c}\text { Axenic } \\
\text { Cultures } \\
{[\%]}\end{array}$} & \multicolumn{2}{|c|}{ Contamination } & \multirow{2}{*}{$\begin{array}{l}\text { Shoot } \\
\text { Length } \\
{[\mathrm{mm}]}\end{array}$} & \multirow[b]{2}{*}{$\begin{array}{l}\text { No. of } \\
\text { Leaves }\end{array}$} & \multirow{2}{*}{$\begin{array}{c}\text { Multiplication } \\
\text { Ratio }\end{array}$} & \multirow[b]{2}{*}{$\begin{array}{c}\text { Rooting } \\
{[\%]}\end{array}$} & \multirow{2}{*}{$\begin{array}{c}\text { Ex Vitro } \\
\text { Survival } \\
\text { [\%] }\end{array}$} \\
\hline & & $\begin{array}{c}\text { Fungal } \\
{[\%]}\end{array}$ & $\begin{array}{c}\text { Bacterial } \\
{[\%]}\end{array}$ & & & & & \\
\hline 0.4 & $10.0 \mathrm{a}$ & $90.0 \mathrm{~b}$ & $0.0 \mathrm{a}$ & $70 \mathrm{a}$ & $44 \mathrm{a}$ & $6.0 \mathrm{a}$ & $100 \mathrm{a}$ & $100 \mathrm{a}$ \\
\hline 0.6 & $20.0 \mathrm{a}$ & $60.0 \mathrm{~b}$ & $20.0 \mathrm{ab}$ & $55 \mathrm{ab}$ & $34 \mathrm{a}$ & $5.0 \mathrm{a}$ & $100 \mathrm{a}$ & $100 \mathrm{a}$ \\
\hline 0.8 & $40.0 \mathrm{a}$ & $20.0 \mathrm{a}$ & $40.0 \mathrm{~b}$ & $40 \mathrm{~b}$ & $10 \mathrm{~b}$ & $2.0 \mathrm{~b}$ & $100 \mathrm{a}$ & $100 a^{1}$ \\
\hline
\end{tabular}

${ }^{1}$ means in columns followed by the same letter do not differ significantly according to Fisher's test at $p \leq 0.05$.

\section{Discussion}

Micropropagation must be performed under aseptic conditions, as any microorganisms present in the culture vessel will compete with the plant for nutrients. Therefore, one of the key steps when developing a micropropagation protocol is to develop a successful surface sterilization method of the explants. Optimal disinfection conditions vary depending on the plant material, as various plant species or explant types have different tolerance against chemicals used for the elimination of microbes. This is due to the different coverage of plants with protective hair and/or the thickness of the cuticle layer, as well as the diverse anatomical structure of individual organs.

In Dicentra, all leaves are in a basal rosette, close to the soil/gardening substrate, which hinders the disinfection process. At the same time, cautious treatments are required not to damage the 
delicate meristems. This is the first report on surface sterilization of vegetative organs in $D . \times$ hybrida. Lee and Lee [5] described a disinfection protocol for seeds of a closely related species-Lamprocapnos spectabilis (L.) Fukuhara, based on the treatment with 70\% (v/v) ethanol (1 $\mathrm{min})$ and $1.5 \%(v / v) \mathrm{NaOCl}$ (5 min), but failed to describe the efficiency of this protocol. Unfortunately, information on disinfection success is often neglected in research papers related to micropropagation, even though this step is essential for establishing a tissue culture system [6]. The obtained here results $(10-40 \%$ of axenic cultures) are satisfying and comparable with those reported with Kalanchoe tubiflora (Harvey) Hamet [7]. Based on the present observations (Table 1), it can be suggested that $\mathrm{NaOCl}$ is more effective in eliminating fungal microorganisms than bacterial ones. The reported decrease in shoot length, number of leaves, and multiplication ratio in bleeding heart treated with the highest concentration of $\mathrm{NaOCl}(0.8 \%)$ is probably a result of meristem damage during the exposition.

Medium composition is another key factor affecting the efficiency of a micropropagation protocol. The present study demonstrated that $D . \times$ hybrida can be easily propagated in vitro even in a classical MS medium devoid of plant growth regulators (PGRs), although the addition of KIN, which activates the existing meristems, improves the development of microshoots. A positive influence of KIN was also observed with axillary shoot proliferation from aseptic seedlings of Nepeta nuda subsp. albiflora [8]. Interestingly, caulogenesis and rhizogenesis can be induced simultaneously in bleeding heart 'Amore Rose', without exogenous application of auxins, which is not the case with every plant species [9]. The use of meristematic explant and lack of callus development suggest maintaining trueness-to-type with the mother plant, although more studies are needed to confirm this [10]. These findings suggest that $D . \times$ hybrida is a good model organism for further studies related to in vitro cultures. Increasing the concentration of KIN or the addition of an auxin could increase the proliferation rate even more, as described with other plant species [11].

Acclimatization to ex vitro conditions is a critical step in any micropropagation protocol as plants produced in vitro often have dysfunctional stomata and a thin cuticle layer [12]. In the present study, all of the plantlets survived acclimatization to the glasshouse and mainatined high quality. This highlights the usefulness of the described here protocol in the large scale reproduction of $D . \times$ hybrida.

\section{Conclusions}

This is the first complete report on the micropropagation of Dicentra $\times$ hybrida. The developed here protocol can be recommended for large scale reproduction of this species with possible extension to other members of the Dicentra genus. Further studies should focus on inducing adventitious organogenesis from leaf explants of the in vitro-derived plant material.

Acknowledgments: No funding was received.

Conflicts of Interest: The author declares no conflict of interest.

\section{Abbreviations}

The following abbreviations are used in this manuscript:

$\begin{array}{ll}\text { KIN } & \text { Kinetin } \\ \mathrm{MS} & \text { Murashige and Skoog medium } \\ \mathrm{NaOCl} & \text { Sodium hypochlorite } \\ \text { PGRs } & \text { Plant growth regulators }\end{array}$

\section{References}

1. Thorpe, T. History of plant tissue culture. Methods Mol. Biol. 2012, 877, 9-27, doi:10.1007/978-1-61779-818$4 \_2$.

2. Kulus, D. Selected aspects of ornamental plants micropropagation in Poland and worldwide. Life Sci. 2015, 4, 154-196, doi:10.13140/RG.2.1.5086.8082.

3. Korlipara, H. Dicentra Plant Named 'Amore Rose'. U.S. Patent USPP25623P3, 2015. 
4. Murashige, T.; Skoog, F. A revised medium for rapid growth and bio assays with tobacco tissue cultures. Physiol. Plant. 1962, 15, 473-497, doi:10.1111/j.1399-3054.1962.tb08052.x.

5. Lee, K.P.; Lee, D.W. Somatic embryogenesis and plant regeneration from seeds of wild Dicentra spectabilis (L.) Lem. Plant Cell Rep. 2003, 22, 105-109, doi:10.1007/s00299-003-0642-5.

6. Teixeira da Silva, J.; Kulus, D.; Zhang, X.; Zeng, S.; Ma, G.; Piqueras, A. Disinfection of explants for saffron (Crocus sativus L.) tissue culture. Environ. Exp. Biol. 2016, 14, 183-198, doi:10.22364/eeb.14.25.

7. Kulus, D. Micropropagation of Kalanchoe tubiflora (Harvey) Hamet. Sci. Nat. Tech. 2015, 9, 1-8, doi:10.17306/J.NPT.2015.1.14.

8. Erdağ, B.; Emek, Y.; Kuzu, İ.; Bağdatl, M.N. Axillary shoot proliferation from aseptic seedlings of Nepeta nuda subsp. albiflora. J. Med. Plant Stud. 2018, 6, 34-37.

9. Gonin, M.; Bergougnoux, V.; Nguyen, T.D.; Gantet, P.; Champion, A. What makes adventitious roots? Plants 2019, 8, 240, doi:10.3390/plants8070240.

10. Miler, N.; Kulus, D.; Sliwinska, E. Nuclear DNA content as an indicator of inflorescence colour stability of in vitro propagated solid and chimera mutants of chrysanthemum. Plant Cell Tissue Organ Cult. 2020, doi:10.1007/s11240-020-01929-9.

11. Aremu, A.O.; Fawole, O.A.; Makunga, N.P.; Masondo, N.A.; Moyo, M.; Buthelezi, N.M.D.; Amoo, S.O.; Spíchal, L.; Doležal, K. Applications of cytokinins in horticultural fruit crops: Trends and future prospects. Biomolecules 2020, 10, 1222, doi:10.3390/biom10091222.

12. Mani, M.; Rasangam, L.; Selvam, R.; Shekhawat, M.S. Micro-morpho-anatomical mechanisms involve in epiphytic adaptation of micropropagated plants of Vanda tessellata (Roxb.) Hook. ex G. Don. Microsc. Res. Tech. 2020, doi:10.1002/jemt.23630.

Publisher's Note: MDPI stays neutral with regard to jurisdictional claims in published maps and institutional affiliations.

(C) 2020 by the authors. Submitted for possible open access publication under the terms and conditions of the Creative Commons Attribution (CC BY) license (http://creativecommons.org/licenses/by/4.0/). 